\title{
Intragastric Botox Injection Barely to the Antrum vs. Diet: A Comparative Study
}

\section{Sadece Antruma Yapılan Intragastrik Botoks Enjeksiyonu Diyete Karşı: Karşılaştırmalı Bir Çalışma}

\section{Benan Kasapoğlu' ${ }^{\text {, (1) Ahmet Yozgat }}{ }^{2}$, (1) Murat Kekilli}

'Division of Gastroenterology, Department of Internal Medicine, Lokman Hekim University Faculty of Medicine, Ankara, Turkey ${ }^{2}$ Division of Gastroenterology, Department of Internal Medicine, Ufuk University Faculty of Medicine, Ankara, Turkey ${ }^{3}$ Division of Gastroenterology, Department of Internal Medicine, Gazi University Faculty of Medicine, Ankara, Turkey

\begin{abstract}
Introduction: In this study, we aimed to report the clinical outcomes of antral BTX-A injection in the absence of widespread injections and compare the results with the control cases who only were under a diet program without any invasive procedure.

Methods: Intragastric BTX-A injection was performed in 42 patients. Meanwhile, 38 age- and gender-matched patients who started a new diet program were included in the control group. Only the patients with a body mass index (BMI) between $30 \mathrm{~kg} / \mathrm{m}^{2}$ and $35 \mathrm{~kg} / \mathrm{m}^{2}$ were included for analysis.

Results: In total, 42 patients (11 males, 31 females) who had intragastric BTX-A injection and 38 patients (8 males, 30 females) who were under a diet program were included in this study. In the group administered with BTX-A, the minimum weight loss in this 5 -month period was $7 \mathrm{~kg}$, and the maximum weight lost was $19 \mathrm{~kg}$ with a mean of $14.48 \pm 2.20$ $\mathrm{kg}$; while the minimum weight loss in this 5 -month period was $5 \mathrm{~kg}$ and the maximum weight lost was $13 \mathrm{~kg}$ with a mean of $10.78 \pm 2.09 \mathrm{~kg}$ in the control group $(\mathrm{p}=0.001)$.

Discussion and Conclusion: Intragastric BTX-A injection, barely to the antrum, was determined to be more effective in inducing significant weight loss in patients with grade 1 obesity than only diet and exercise. Approximately 10\%-15\% weight loss was achieved after antral BTX-A injection in about 3 months without any significant adverse events. In that aspect, intragastric BTX-A injection could be a promising way of inducing weight loss in obese patients. Keywords: Antrum; Intragastric BTX-A Injection; Obesity
\end{abstract}

$\mathrm{O}$ besity is a chronic disease affecting $10 \%-15 \%$ of people worldwide; it is one of the main risk factors of some sion, and obstructive sleep apnea. Increasing prevalence and morbidity rates make obesity an important health metabolic disorders such as diabetes mellitus, hyperten- 
recently in the development of several novel surgical and endoscopic treatment options for obesity, the success rates and long-term outcomes have remained conflicting.

Botulinum toxin (BTX) is the most powerful known inhibitor of muscular contraction by interfering with acetylcholine release in the neuromuscular plaque in both striated and smooth muscles. ${ }^{[2]}$ Antral BTX-A injection was first suggested as an endoscopic treatment of obesity approximately 20 years ago. ${ }^{[3]}$ With the inhibition of the acetylcholine-mediated peristalsis after BTX-A injection, gastric emptying is expected to be slowed down inducing earlier satiety. Elevated gastric emptying time resulting in weight reduction has also been demonstrated in experimental studies with antral BTX-A injection. ${ }^{[4]}$ However, the clinical data are conflicting regarding the outcomes of this endoscopic treatment. Different responses of intragastric BTX-A administration have been reported in previous studies, which may be associated with the differences in injection sides or techniques or patient selections.

In this study, we aimed to compare the clinical outcomes of antral BTX-A injection in the lack of widespread injections through the fundus with the control cases who only were under a diet program without any invasive procedure.

\section{Materials and Methods}

Intragastric BTX-A injection was performed in 42 patients between June 2019 and June 2020 in Lokman Hekim Akay Hospital, Ankara, Turkey. Age- and gender-matched 38 patients who started a weight management program on the same period were included in the control group. The records of patients were evaluated retrospectively.

BTX-A injection was performed in volunteer patients, who were older than 18 years of age and having a body mass index (BMI) of over $30 \mathrm{~kg} / \mathrm{m}^{2}$ and lower than $35 \mathrm{~kg} / \mathrm{m}^{2}$. All patients were asked to come once in every 2 weeks. The body weights and adverse events were then recorded. Body weights were determined on the same scale. Exclusion criteria were as follows: pregnant or lactating women; patients with known chronic systemic diseases such as hypertension, diabetes mellitus, coronary artery disease, chronic obstructive pulmonary disease, chronic renal failure, or cirrhosis; patients who had prior gastric/bariatric surgery; patients with a known history of alcohol or drug abuse, and patients with a known allergy to any ingredients in botulinum toxin products

All patients were informed about BTX-A and its procedure before the injections. During the initial evaluation, before injection, patients were assessed for clinical gastropare- sis, hypothyroidism, clinical gastroesophageal reflux disease, gastric ulcers or cancer, and previous gastric surgery. During endoscopy, in the presence of gastric ulcers or esophagitis, BTX-A injection was not performed. Upper endoscopy was performed with Olympos ${ }^{\circledast}$ video endoscope (Olympos ${ }^{\circledast}$ Video Gastroscope GIF-XTQ160) under intravenous sedation with propofol. A dose of $200 \mathrm{U}$ of BT type $A$ (Allergan, Irvine, Mexico DF) was diluted in $8 \mathrm{~mL}$ of saline solution. It was injected circularly through a sclerotherapy injector needle (TechnoCath ${ }^{\circledR}$ Disposable 23 Gauge $/ 5 \mathrm{~mm}$ Sclerotherapy Needle) into the prepyloric antral gastric wall at 20 sites in a concentric ring $1 \mathrm{~cm}$ apart. Each injection contained $0.5 \mathrm{~mL}$ volume and $6.25 \mathrm{U}$ of BTX-A. After BTX-A injection, all patients were recruited in a 24-week weight management program.

During follow-ups, clinical symptoms of gastroparesis (nausea, vomiting, early satiety, and abdominal distension) were recorded at 1, 4, and 12 weeks after treatment. Body weight was measured monthly after treatment. All patients were treated only with botulinum toxin injection; they were not under any other medications that may induce weight loss.

In total, 38 age- and gender-matched patients who were recruited in the same 24-week weight management program with the group injected with BTX-A on the same period were included in the control group. All patients were asked to come once in every 2 weeks. They were not under any other medications that may induce weight loss.

Patients with lacking file information or follow-up data were excluded from the study. Patients who were under any medications that may induce weight loss or patients having any chronic diseases such as diabetes mellitus, hypertension, or cardiovascular diseases were excluded from the study.

Body mass index was calculated in all participants using

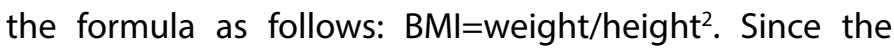
study was retrospective in nature, informed consents could not be obtained, so the patients' privacy information was removed from the data analysis

\section{Statistical Analyses}

For statistical analysis, the Statistical Package for Social Sciences (SPSS) 21.0 software (SPSS Inc., Chicago, IL, USA) package program was used. The normality of the distribution of the data was analyzed using the Kolmogorov-Smirnov test. Descriptive statistical methods are then performed. Data were presented as mean \pm standard deviation or count (percentage). The body mass indexes of study participants at admission and on the $3^{\text {rd }}$ or $6^{\text {th }}$ month after the injec- 
Table 1. The body mass index of study participants at admission and on the $3^{\text {rd }}$ month and $6^{\text {th }}$ month after the procedure

\begin{tabular}{lcccc}
\hline & $\begin{array}{c}\text { At } \\
\text { admission }\end{array}$ & $\begin{array}{c}\text { On the } \\
\mathbf{3}^{\text {rd }} \text { month }\end{array}$ & $\begin{array}{c}\text { On the } \\
\mathbf{6}^{\text {th }} \text { month }\end{array}$ & p \\
\hline BMl $\left(\mathrm{kg} / \mathrm{m}^{2}\right)$ & & & & \\
Botox group $(\mathrm{n}=42)$ & $32.17 \pm 1.20$ & $26.93 \pm 1.26$ & $24.22 \pm 1.14$ & $\mathbf{0 . 0 0 1}$ \\
Control group $(\mathrm{n}=38)$ & $31.98 \pm 0.99$ & $28.24 \pm 1.44$ & $27.34 \pm 1.88$ & $\mathbf{0 . 0 0 1}$ \\
$\mathrm{P}$ & 0.55 & 0.001 & 0.001 & \\
\hline
\end{tabular}

BMI: Body Mass Index.

Table 2. Distributions of initial weight and the weights of the participants on the $5^{\text {th }}$ month of follow-up

\begin{tabular}{lccc}
\hline & $\begin{array}{c}\text { Botox group } \\
(\mathbf{n}=\mathbf{4 2})\end{array}$ & $\begin{array}{c}\text { Control group } \\
(\mathbf{n}=\mathbf{3 8})\end{array}$ & $\mathbf{p}$ \\
\hline Initial weight & & & \\
Weight on the $1^{\text {st }}$ month & $86.32 \pm 5.84$ & $84.89 \pm 5.57$ & $\mathbf{0 . 3 6}$ \\
Weight on the $2^{\text {nd }}$ month & $78.96 \pm 5.89$ & $80.68 \pm 5.30$ & $\mathbf{0 . 2 9}$ \\
Weight on the $3^{\text {rd }}$ month & $75.64 \pm 5.92$ & $77.46 \pm 5.27$ & $\mathbf{0 . 2 8}$ \\
Weight on the $4^{\text {th }}$ month & $72.96 \pm 5.64$ & $75.90 \pm 5.79$ & $\mathbf{0 . 0 0 1}$ \\
Weight on the $6^{\text {th }}$ month & $71.02 \pm 5.71$ & $75.18 \pm 5.97$ & $\mathbf{0 . 0 0 1}$ \\
\hline
\end{tabular}

tion were compared using one-sample t-test. Two-sample t-test (also known as the independent samples t-test) was performed to compare the continuous data between or among groups. Chi-square test was used to compare the categorical data between groups. The significance level was set at $p<0.05$.

\section{Results}

In total, 42 patients (11 males, 31 females) who had intragastric BTX-A injection and 38 patients ( 8 males, $30 \mathrm{fe}-$ males) who were under a weight management program were included in this study. No significant difference was observed between study and control groups as regards gender $(p=0.178)$. The mean age of the patients in Botox and control groups were $38.02 \pm 4.42$ years and $37.12 \pm 5.64$ years, respectively $(p=0.467)$.

Meanwhile, significant decreases were noted in terms of $\mathrm{BMI}$ among patients on the $3^{\text {rd }}$ and $6^{\text {th }}$ month of follow-up compared at admission in both groups (Table 1). Distributions of initial weights and the weights of the participants on the $6^{\text {th }}$ month are summarized in Table 2 . In every month, participants were noted to lose weight. The weight loss journey of the participants from the $1^{\text {st }}$ month of the study is summarized in Table 3 and Figure 1. The minimum weight loss for the 6-month period was $7 \mathrm{~kg}$, and the maximum weight loss was $18 \mathrm{~kg}$ with a mean of $14.48 \pm 2.20 \mathrm{~kg}$ in BTX-A group; while in the control group,
Table 3. The weight loss by study participants from the $1^{\text {st }}$ month of the study

\begin{tabular}{cccc}
\hline & $\begin{array}{c}\text { Botox group } \\
(\mathbf{n = 4 2 )}\end{array}$ & $\begin{array}{c}\text { Control group } \\
(\mathbf{n = 3 8 )}\end{array}$ & $\mathbf{p}$ \\
\hline$\Delta 1$ & $7.36 \pm 1.80$ & $5.09 \pm 1.54$ & $\mathbf{0 . 0 0 1}$ \\
$\Delta 2$ & $4.32 \pm 1.24$ & $3.30 \pm 1.44$ & $\mathbf{0 . 0 2}$ \\
$\Delta 3$ & $2.68 \pm 0.90$ & $2.09 \pm 127$ & 0.34 \\
$\Delta 4$ & $1.42 \pm 0.44$ & $1.18 \pm 0.78$ & 0.68 \\
$\Delta 6$ & $14.88 \pm 2.26$ & $10.24 \pm 3.49$ & $\mathbf{0 . 0 0 1}$ \\
\hline
\end{tabular}

$\Delta 1$ : Weight loss on the $1^{\text {st }}$ month; $\Delta 2$ : Weight loss on the $2^{\text {nd }}$ month; $\Delta 3$ : Weight loss on the $3^{\text {rd }}$ month; $\Delta 4$ : Weight loss on the $4^{\text {th }}$ month; $\Delta 6$ : Weight loss throughout the 6 months after injection or starting weight management program.

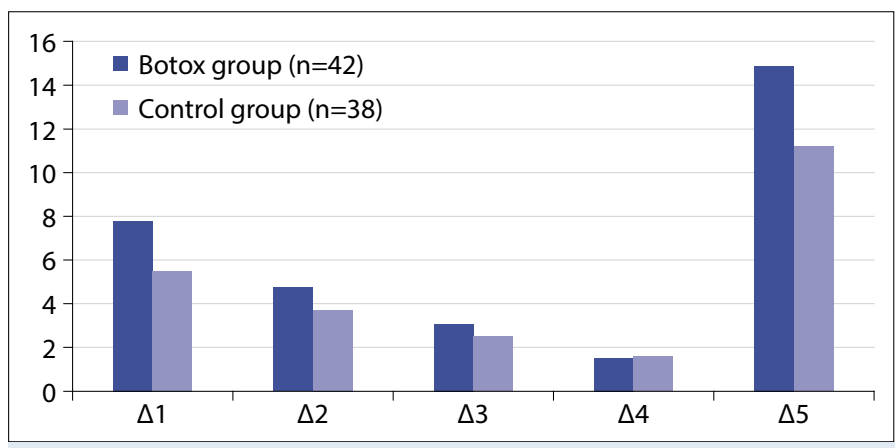

Figure 1. Distributions of the weight lost by study participants from the $1^{\text {st }}$ month of the study.

the minimum weight loss in the 6-month period was $5 \mathrm{~kg}$ and the maximum weight lost was $13 \mathrm{~kg}$ with a mean of $10.78 \pm 2.09 \mathrm{~kg}(\mathrm{p}=0.001)$.

Five (14.7\%) patients reported early satiety, abdominal distension, or transient anorexia after BTX-A injection. None of these symptoms were severe enough to require symptomatic treatment administration.

\section{Discussion}

With the rising prevalence of obesity and its associated complications, finding new treatment options has become essential. In this study, we have determined that intragastric BTX-A injection was more effective in inducing weight loss than diet in patients with grade 1 obesity. The most important characteristic feature of this study was that we did not perform widespread injections through the fundus and compared the outcomes with the patients under diet.

Satiety and appetite control is a complex process. Gastric distention and accommodation and some hormones such as cholecystokinin, bombesin, somatostatin, glucagon-like peptide-1, and ghrelin play important roles in appetite control. ${ }^{[5]}$ Gastric accommodation is the relaxation of the gastric wall in response to food intake. Impairment in gas- 
tric accommodation has been associated with induced satiety and sensation of fullness. Increased gastric accommodation is positively correlated with the volume needed to suppress food intake. The speed with which the stomach empties also depends on the nature of the food, its osmolality, and its chemical composition. Small temporary increases in gastric emptying time have been reported after antral BTX-A injections. ${ }^{[6,7]}$ Although we did not analyze the gastric emptying time in patients, we believe that statistically significant weight loss obtained with BTX-A injection was associated with the altered gastric accommodation. Approximately $10 \%-15 \%$ weight loss was achieved after antral BTX-A injection in about 3 months in the absence of significant adverse events. The degree of weight loss in a month decreased in time and after 3 months.

The data on the clinical outcomes of intragastric BTX-A injection remain controversial in the literature. In the study of Foschi et al., ${ }^{[8]} 24$ morbidly obese patients were blindly randomized to re-ceive 200 IU BTX or placebo into the antrum and fundus of the stomach by intraparietal endoscopic administration. They reported that 8 weeks after BTX injection, in the BTX group, the patients had significantly higher weight loss and BMI reduction and a higher satiety score than controls. Further-more, BTX patients showed a significantly greater reduction in maximal gastric capacity for liquids and a greater prolongation in gastric emptying time. No significant side effects or neurophysiologic changes were found. In an experimental study, Park et al. ${ }^{[9]} \mathrm{com}$ pared the following three groups: BTX group consisting of 15 obese rats which were administered with $20 \mathrm{U}$ of BTX into the gastric antrum, the saline group consisting of 15 obese rats injected with $20 \mathrm{U}$ of saline, and the control group consisting of 10 obese rats that did not receive any surgical intervention. As per their findings, it was determined that the bodyweight of the BTX group was significantly lower than those of the other groups at 6 weeks after the operation. They also reported that the gastric emptying time was sig-nificantly delayed in the BTX group. Meanwhile, de Moura et al. ${ }^{[10]}$ compared the two groups: BTX-A, in which 200 units of BTX-A were injected into the gastric antrum and body, and control, in which the same injections were performed with $0.9 \%$ saline in the preoperative treatment of super-obese patients. They reported that the patients in both groups showed significant weight loss through-out the study, but there were not any significant differences between the groups regarding weight loss or change in BMI. The authors concluded that the intragastric injection of BTX-A was not an effective endoscopic treatment for preoperative weight loss in super-obese patients, which was also discussed further by Ribeiro IB et al. ${ }^{[11]}$ We injected BTX-A to the antrum barely in patients with a BMI be-tween $30 \mathrm{~kg} / \mathrm{m}^{2}$ and $35 \mathrm{~kg} / \mathrm{m}^{2}$. We did not include the super-obese patients.

Different responses to intragastric BTX-A administration have been reported in previous stud-ies, which may be associated with the differences in injection sides or techniques. ${ }^{[12-14]}$ In a meta-analysis of 8 studies on 115 patients (79 treated vs. 36 placebo), the treatment group was associated with weight loss in a pre/post-comparative approach compared to the placebo group; and the authors concluded that wide-area injection including the fundus or body rather than the antrum only was asso-ciated with weight loss. ${ }^{[12]}$ Similarly, in another systematic review and meta-analysis of four studies, Bustamante et al. ${ }^{[13]}$ concluded that treating obesity with BTA was not effective. However, we did not perform any injections to the fundus but achieved significant weight loss in patients with grade 1 obesity. Patient selection may be an important factor in this difference. Our patients were not super-obese, and we informed all of the patients before the treatment for at least two times. Moreover, re-garding the BMI or age distribution, our population was not a cosmopolite group which may also have some influences in our results.

Ghrelin, an appetite hormone, is mainly secreted from the fundus, and the main rationale for BTX-A injection to the fundus is to decrease the ghrelin secretion. ${ }^{[15]}$ However, to the best of our knowledge, the data regarding the ghrelin levels after BTX-A injection remain limited. In their study on 20 obese patients, Li et al. ${ }^{[16]}$ reported significant body weight and BMI decreases, with signifi-cantly elongated gastric emptying times after endoscopic multi-punctures of BTX-A including fundic injections. The authors also reported a significant decrease in fasting ghrelin levels 4 weeks after BTX-A administration. On the other hand, since muscle structures in the fundus are not as broad as those of the antrum, theoretically, fundus injections may be associated with more adverse events in-cluding perforations. The main limitation of this study was the low number of patients and short follow-up periods.

Though this is not a miracle method, when asked, all patients responded that they were feeling full for a longer time, which induced the compliance of diet. However, all patients shared they were trying to have an appropriate diet for a long time, but had always failed until this time.

In conclusion, barely antral BTX-A injection was more effective in inducing significant weight loss in patients with grade 1 obesity than diet. Approximately $10 \%-15 \%$ weight loss was achieved after antral BTX-A injection in about 3 
months without any significant adverse events. In that aspect, antral BTX-A injection may be a promising way of inducing weight loss in grade 1 obese patients. Further, larger studies with longer follow-up periods are warranted, since this is an endoscopic treat-ment method having less morbidity compared with the more invasive surgical methods.

Peer-review: Externally peer-reviewed.

Authorship Contributions: Concept: BK, AY, MK; Design: BK, AY, MK; Supervision: BK, AY, MK; Data Collection or Processing: BK, AY; Analysis or Interpretation: BK, AY, MK; Literature Search: BK, MK; Writing: BK, MK; Critical Review: BK, AY, MK.

Conflict of Interest: None declared.

Financial Disclosure: The authors declared that this study received no financial support.

\section{References}

1. Arroyo-Johnson C, Mincey KD. Obesity epidemiology worldwide. Gastroenterol Clin North Am 2016;45(4):571-9.

2. Bhutani MS. Gastrointestinal uses of botulinum toxin. Am J Gastroenterol 1997;92(6):929-33.

3. Gui D, De Gaetano A, Spada PL, Viggiano A, Cassetta E, Albanese $A$. Botulinum toxin injected in the gastric wall reduces body weight and food intake in rats. Aliment Pharmacol Ther 2000;14(6):829-34.

4. Coskun H, Duran Y, Dilege E, Mihmanli M, Seymen H, Demirkol MO. Effect on gastric emptying and weight reduction of botulinum toxin-A injection into the gastric antral layer: an experimental study in the obese rat model. Obes Surg 2005;15(8):1137-43.

5. Matthews DR, Hosker JP, Rudenski AS, Naylor BA, Treacher DF, Turner RC. Homeostasis model assessment: insulin resistance and beta-cell function from fasting plasma glucose and insulin concentrations in man. Diabetologia 1985;28(7):412-9.

6. Camilleri M. Gastrointestinal hormones and regulation of gastric emptying. Curr Opin Endocrinol Diabetes Obes 2019;26(1):3-10.

7. Vargas EJ, Bazerbachi F, Calderon G, Prokop LJ, Gomez V,
Murad $\mathrm{MH}$, et al. Changes in time of gastric emptying after surgical and endoscopic bariatrics and weight loss: A systematic review and meta-analysis. Clin Gastroenterol Hepatol 2020;18(1):57-68.e5.

8. Foschi D, Corsi F, Lazzaroni M, Sangaletti O, Riva P, La Tartara G, et al. Treatment of morbid obesity by intraparietogastric administration of botulinum toxin: a randomized, double-blind, controlled study. Int J Obes (Lond) 2007;31(4):707-12.

9. Park JS, Zheng HM, Kim JM, Kim CS, Jeong S, Lee DH. The effect of intragastric administration of botulinum toxin type a on reducing adiposity in a rat model of obesity using micro-CT and histological examinations. Gut Liver 2017;11(6):798-806.

10. de Moura EGH, Ribeiro IB, Frazão MSV, Mestieri LHM, de Moura DTH, Dal Bó CMR, et al. EUS-guided intragastric injection of botulinum toxin a in the preoperative treatment of super-obese patients: a randomized clinical trial. Obes Surg 2019;29(1):32-9.

11. Ribeiro IB, de Moura DTH, de Moura EGH. Response to letter to the editor re: "EUS-guided intragastric injection of botulinum toxin a in the preoperative treatment of super-obese patients: a randomized clinical trial". Obes Surg 2019;29(3):1016-7.

12. Bang CS, Baik GH, Shin IS, Kim JB, Suk KT, Yoon JH, et al. Effect of intragastric injection of botulinum toxin $A$ for the treatment of obesity: a meta-analysis and meta-regression. Gastrointest Endosc 2015;81(5):1141-9.

13. Bustamante F, Brunaldi VO, Bernardo WM, de Moura DTH, de Moura ETH, Galvão M, et al. Obesity treatment with botulinum toxin-a is not effective: a systematic review and meta-analysis. Obes Surg 2017;27(10):2716-23.

14. Brunaldi VO, Bustamante F, Bernardo WM, de Moura EGH. Response to "The forgotten fundus-obesity treatment with botulinum toxin-a is not effective: a systematic review and meta-analysis". Obes Surg 2018;28(1):264-5.

15. Alamri BN, Shin K, Chappe V, Anini Y. The role of ghrelin in the regulation of glucose homeostasis. Horm Mol Biol Clin Investig 2016;26(1):3-11.

16. Li L, Liu QS, Liu WH, Yang YS, Yan D, Peng LH, et al. Treatment of obesity by endoscopic gastric intramural injection of botulinum toxin A: a randomized clinical trial. Hepatogastroenterology 2012;59(118):2003-7. 